\title{
ARTICLE OPEN \\ Corrosion of the International Simple Glass under acidic to hyperalkaline conditions
}

\author{
Daniel J. Backhouse ${ }^{1}$, Adam J. Fisher ${ }^{1}$, James J. Neeway ${ }^{2}$, Claire L. Corkhill ${ }^{1}{ }^{1}$, Neil C. Hyatt ${ }^{1}$ and Russell J. Hand (D)
}

\begin{abstract}
Assessment of glass dissolution kinetics, under disposal relevant temperature and pH environments, is required to credibly estimate radionuclide release rates from vitrified radioactive waste. Leaching of the International Simple Glass (ISG) under acidic to hyperalkaline conditions was examined. Forward rate measurements have been obtained using the dynamic leaching SPFT protocol and rate parameters for $\mathrm{B}, \mathrm{Na}$ and $\mathrm{Si}$ in the basic regime; errors in rates predicted using these parameters at high $\mathrm{pH}$ and temperature are significant because the fitting uses logarithmic data. Longer term behaviour under hyperalkaline conditions, representative of some disposal environments, was investigated using the $\mathrm{PCT}$ and $\mathrm{MCC}-1$ static leaching protocols with $\mathrm{Ca}(\mathrm{OH})_{2}$ solutions for up to 120 days (PCT) and 720 days (MCC-1). In hyperalkaline conditions dissolution was incongruent for all elements and the presence of alternating zirconia-rich and zirconia-poor alteration layers was observed on all leached monoliths, indicating the occurrence of a self-organisation phenomenon during leaching.
\end{abstract}

npj Materials Degradation (2018)2:29; doi:10.1038/s41529-018-0050-5

\section{INTRODUCTION}

Radioactive waste produced from the reprocessing of spent nuclear fuel in the UK and other countries is immobilized in alkaliborosilicate glasses, and is destined for final disposal in a deep (typically $>500 \mathrm{~m}$ ) geological disposal facility (GDF). In this environment, the release of radionuclides to the geo-sphere and potentially the bio-sphere will be controlled by dissolution of the glass matrix by groundwater. Developing an understanding of glass dissolution is therefore critical to building a robust safety case for geological disposal, whereby the integrity of the waste must be ensured for up to 100,000 years. In particular, an assessment of the kinetics of glass dissolution is required under relevant temperature and groundwater $\mathrm{pH}$ environments, to credibly estimate the radionuclide release rate.

In the UK, co-location of the geological repository for vitrified high level waste $(H L W)$ with the repository for intermediate level waste (ILW), containing primarily cemented waste in a cementitious backfill, is being considered. ${ }^{1}$ Thus possible interactions of the vitrified HLW with a highly alkaline plume originating from the ILW repository have to be taken into account. In addition, in the future, some UK ILW may be vitrified and, due to the difference in heat-load requirements for vault spacing, such vitrified ILW will probably be disposed in the same repository as cemented ILW. Hence understanding the leaching behaviour of vitrified waste glasses under the hyperalkaline conditions imposed by a cementitious environment is important for the development of the repository safety case.

The dissolution kinetics of alkali-borosilicate glass in water are a function of glass composition, temperature, $\mathrm{pH}$ and solution chemistry. The forward dissolution rate is controlled by ionexchange between the glass network modifier cations (alkali and to a lesser extent alkaline earth) and positively charged water species, and by the hydrolysis of the borosilicate glass network. ${ }^{2,3}$
Here, the glass dissolves at its maximum rate until the rate drops because of chemical affinity effects (due to concentrations of dissolved silicon in solution) reduce the thermodynamic driving force for dissolution and/or a passivating alteration layer forms on the surface of the glass). The chemical affinity effect can be described through the application of Transition State Theory ${ }^{4}$ (TST). The modified version of this kinetic rate equation for glass (originally applied to aluminosilicate minerals by Aagaard \& Helgeson, ${ }^{5}$ assuming that the rate-limiting reaction is the dissolution of the silicate network to form orthosilicic acid ${ }^{6}$ $\left(\mathrm{H}_{4} \mathrm{SiO}_{4}\right)$, is given by:

$$
r=k_{0} \nu_{i} a_{\mathrm{H}+}^{\eta} \exp \left(-\frac{E_{a}}{R T}\right)\left[1-\left(\frac{Q}{K_{g}}\right)^{\sigma}\right]
$$

where $r$ is the dissolution rate and $k_{0}$ is the forward rate constant (both in $\mathrm{g} \mathrm{m}^{-2} \mathrm{~d}^{-1}$ ), $v_{i}$ is the stoichiometric coefficient for element $i, E_{a}$ is the activation energy in $\mathrm{J} \mathrm{mol}^{-1}, R$ is the molar gas constant $\left(8.314 \mathrm{~J} \mathrm{~mol}^{-1} \mathrm{~K}^{-1}\right), T$ is the absolute temperature $(\mathrm{K}), a_{\mathrm{H}+}$ is the hydrogen ion activity, $\eta$ is the $\mathrm{pH}$ power-law coefficient, $Q$ is the ion activity product, $K_{g}$ is the pseudo-equilibrium constant (solubility constant) for the rate-controlling reaction and $\sigma$ is the Temkin coefficient/rate of decomposition of the activated complex (assumed to be unity for borosilicate glass). ${ }^{7}$ Hence, the saturation state of the solution is described by the terms in square brackets in Eq. (1). The single-pass-flow-through (SPFT) methodology, which is designed to avoid chemical affinity effects and the formation of alteration layers, enables assessment of the forward rate when the saturation term equals unity. Providing that forward dissolution rates are measured in experiments performed over a range of temperature and $\mathrm{pH}$ values, the SPFT methodology enables the determination of the rate law parameters $k_{0}, E_{a}$ and $\eta$. Obtaining accurate rate law parameters is important since these parameters can be used as input to kinetic models of glass

\footnotetext{
${ }^{1}$ ISL, Department of Materials Science \& Engineering, University of Sheffield, Sir Robert Hadfield Building, Mappin Street, Sheffield S1 3JD, UK and ${ }^{2}$ Energy and Environment Directorate, Pacific Northwest National Laboratory, Richland, WA 99352, USA

Correspondence: Russell J. Hand (r.hand@sheffield.ac.uk)
}

Received: 1 May 2018 Revised: 9 August 2018 Accepted: 17 August 2018

Published online: 10 September 2018 

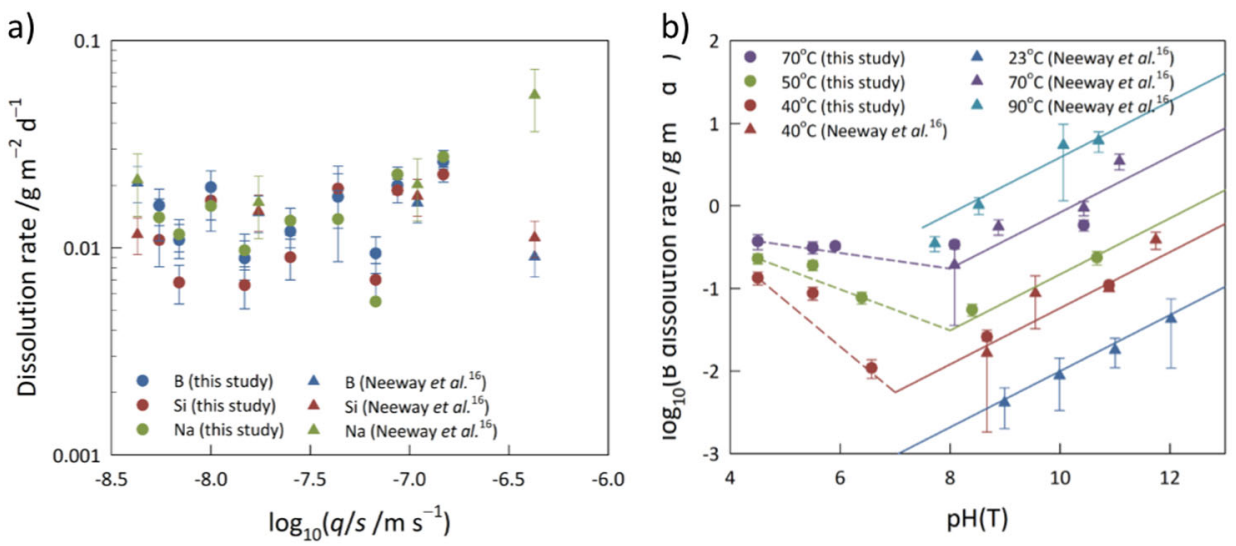

c)

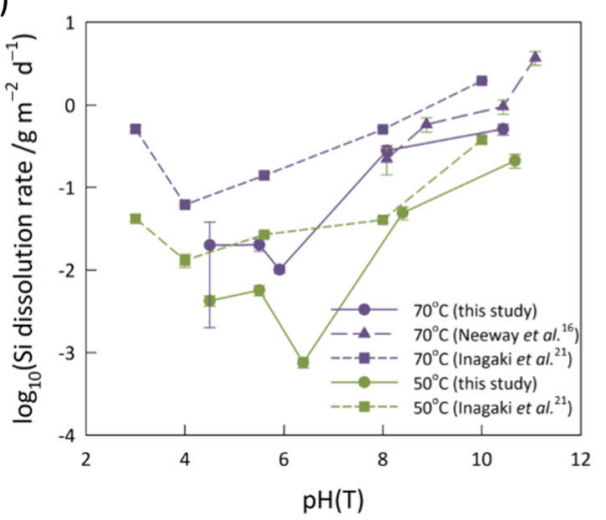

d)
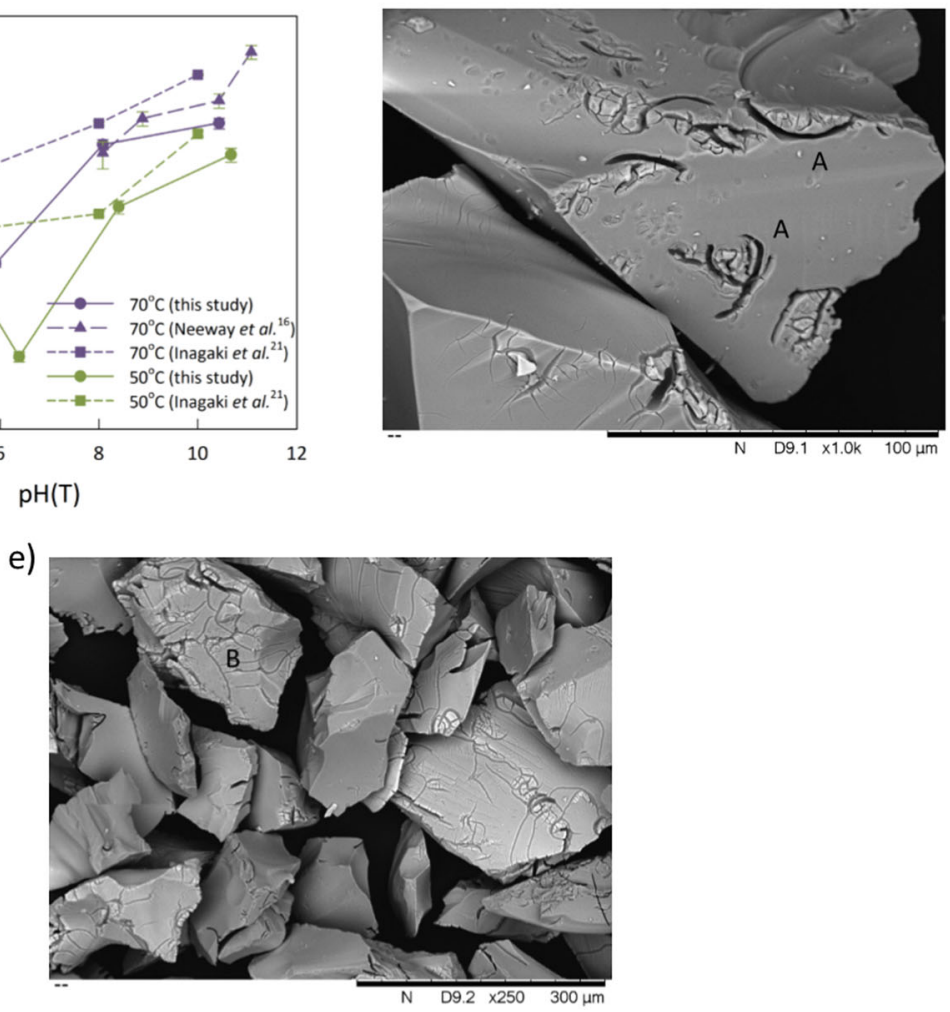

Fig. 1 a B \& Si dissolution rates $\left(\mathrm{g} \mathrm{m}^{-2} \mathrm{~d}^{-1}\right)$ versus $\log _{10}\left[(q / S) /\left(\mathrm{m} \mathrm{s}^{-1}\right)\right]$ where $q$ is flow-rate and $S$ is sample-surface-area at $\mathrm{pH}(\mathrm{RT}) 9$ and $40^{\circ} \mathrm{C}$ determined from SPFT showing data from this study and Neeway et al. ${ }^{16}$ Error bars are the standard error calculated using Eqs. (7)-(8); $\mathbf{b}$ Compiled forward dissolution rates using data from this study and from Neeway et al. ${ }^{16}$ showing $\log _{10}\left[R_{\mathrm{B}} /\left(\mathrm{g} \mathrm{m}^{-2} \mathrm{~d}^{-1}\right)\right]$ versus $\mathrm{pH}(\mathrm{modelled} \mathrm{at}$ experimental temperature) from all experiments. The solid lines are obtained from a multiple linear regression fit to the data in the basic regime ( $\mathrm{pH} 8-12)$ whereas dashed lines in the acidic regime are a guide to the eye. Error bars are the standard error calculated using Eqs. (7)(8); c Si forward rate data compared to other studies; d, e particles after 100 days SPFT at $\mathrm{pH}(\mathrm{RT}) 11,40^{\circ} \mathrm{C} \& \log { }_{10}\left[(q / S) /\left(\mathrm{m} \mathrm{s}^{-1}\right)\right]=-6.81$, features $A$ in (d) are indicative of localised preferential attack; features $B$ in (e) appear to be dehydration cracks

dissolution for safety assessments of the geological disposal of nuclear waste.

Understanding the effects of the chemistry of the disposal environment on glass dissolution are also important. In hyperalkaline conditions, such as those expected in a UK disposal environment, borosilicate glass durability tends to be relatively poor. Our previous work on the performance of a model ILW glass in saturated $\mathrm{Ca}(\mathrm{OH})_{2}$ solutions at $50^{\circ} \mathrm{C}$ and $90^{\circ} \mathrm{C}(\mathrm{pH}(\mathrm{RT})=12.5)$, representing a cementitious environment, demonstrated that the presence of $\mathrm{Ca}$ leads to the formation of relatively protective alteration products on the glass surface..$^{8-11}$ These results together with those of Andriambololona et al. ${ }^{12}$ and Chave et al. ${ }^{13}$ demonstrate the importance of $\mathrm{Ca}$ in determining the behaviour of the glass studied under such $\mathrm{pH}$ conditions. Meanwhile Gin et al. ${ }^{14}$ have shown that at $\mathrm{pH}\left(90^{\circ}\right)=11.5$ in a $\mathrm{KOH}$ solution the international simple glass (ISG) dissolves congruently. However Ca $(\mathrm{OH})_{2}$ solutions will result in precipitation in both the inlet and outlet SPFT experiments and thus the effects of $\mathrm{Ca}$ have been assessed using the PCT and MCC-1 protocols.

ISG, which has been developed for international researchers for use in glass dissolution research, ${ }^{15}$ is a six-component, nonradioactive alumino-borosilicate glass with nominal composition $12.7 \mathrm{Na}_{2} \mathrm{O} \cdot 5.7 \mathrm{CaO} \cdot 1.7 \mathrm{ZrO}_{2} \cdot 3.8 \mathrm{Al}_{2} \mathrm{O}_{3} \cdot 16.0 \mathrm{~B}_{2} \mathrm{O}_{3} \cdot 60.1 \mathrm{SiO}_{2}$ (mol\%) simplified from the French inactive surrogate of the R7T7 nuclear waste, SON68. Here we report on the assessment of the forward rate for ISG over a range of $\mathrm{pH}$ values and temperatures, together 
with an evaluation of the rate law parameters. In addition we report on the performance of ISG, at essentially the same $\mathrm{pH}$ as that studied by Gin et al., ${ }^{14}$ but in a $\mathrm{Ca}(\mathrm{OH})_{2}$ imposed high $\mathrm{pH}$ which is more representative of likely disposal conditions in the UK than a $\mathrm{KOH}$ imposed elevated $\mathrm{pH}$.

\section{RESULTS}

Acidic and alkaline conditions-forward dissolution rate and rate law parameter determination under dilute conditions

Investigations to establish suitably high solution flow-rate $(q)$ to sample-surface-area $(S)$ ratios $\left(\log _{10}\left([q / S] /\left(\mathrm{m} \mathrm{s}^{-1}\right)\right]\right)$ to represent dilute conditions and sustain dissolution at the forward rate $(q / S$ sweeps), were first undertaken at $\mathrm{pH}(\mathrm{RT}) 9$ and $40^{\circ} \mathrm{C}$; such

Table 1. Rate parameters for $\mathrm{B}, \mathrm{Na}$ and $\mathrm{Si}$ obtained by linear multivariate regression analysis of SPFT data obtained in the basic regime

\begin{tabular}{llll}
\hline & $\log _{10}\left(k_{0} / \mathrm{g} \mathrm{m}^{-2} \mathrm{~d}^{-1}\right)$ & $\eta$ & $E_{a} / \mathrm{kJ} \mathrm{mol}^{-1}$ \\
\hline $\mathrm{B}$ & $8.62 \pm 0.54$ & $0.34 \pm 0.03$ & $79.5 \pm 3.5$ \\
$\mathrm{Na}$ & $8.79 \pm 0.75$ & $0.34 \pm 0.04$ & $80.3 \pm 4.8$ \\
$\mathrm{Si}$ & $7.95 \pm 0.73$ & $0.38 \pm 0.04$ & $77.4 \pm 4.7$ \\
\hline
\end{tabular}
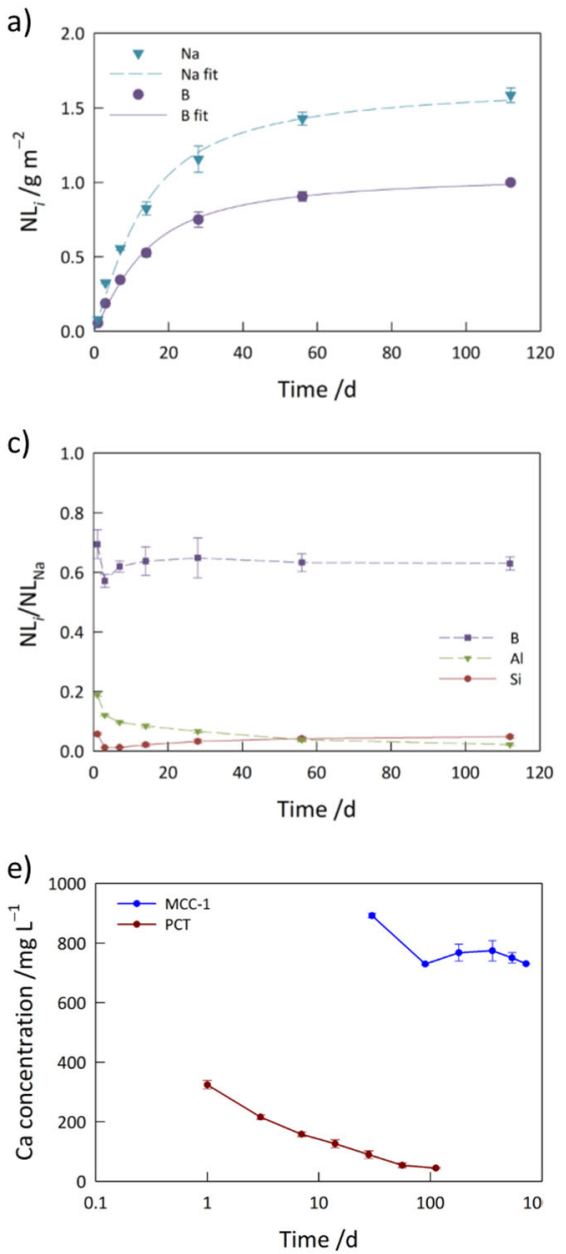

conditions are expected to be representative of the GDF (see Supplementary Table 1). The $q / S$ sweep is shown in Fig. 1a, in which the dissolution rates show little dependence on $q / S$ instead being scattered around mean dissolution rates of $0.0156 \mathrm{~g} \mathrm{~m}^{-2} \mathrm{~d}^{-1}$ (B), $0.0131 \mathrm{~g} \mathrm{~m}^{-2} \mathrm{~d}^{-1}$ (Si) or $0.0145 \mathrm{~g} \mathrm{~m}^{-2} \mathrm{~d}^{-1}(\mathrm{Na})$. This is consistent with the data of Neeway et al. ${ }^{16}$ who reported an invarient response at $90^{\circ} \mathrm{C}$ using the same buffer solutions as those used here. In addition, data showing the determination of steady-state conditions for a selection of experimental conditions are provided in Supplementary Figures $1 \mathrm{a}$ and b. Note that steady-state rates are only representative of a forward rate conditions if they fall on a plateau of a $q / S$ sweep.

The forward dissolution rate $\left(R_{i}\right.$, where $i$ is $\mathrm{Si}, \mathrm{B}$ or $\mathrm{Na}$ ) of the ISG at $\mathrm{pH}(\mathrm{RT}) 9$ and $40^{\circ} \mathrm{C}$ was obtained from the mean value of the dissolution rates measured at $\log _{10}\left[(q / S) /\left(\mathrm{m} \mathrm{s}^{-1}\right)\right]$ in excess of -7.4 . This value for $\log _{10}\left[(q / S) /\left(\mathrm{m} \mathrm{s}^{-1}\right)\right]$ (or one in excess of this value) has been used in numerous other SPFT studies of alkaliborosilicate glass. ${ }^{17-20}$ A $\log _{10}\left[(q / S) /\left(\mathrm{m} \mathrm{s}^{-1}\right)\right]$ value of -7.0 was chosen to conduct rate law determination experiments, with confidence that dilute conditions, enabling the accurate measurement of forward dissolution rates, would be maintained over all temperatures studied; the data of Neeway et al. ${ }^{16}$ indicates that a $\log _{10}\left[(q / S) /\left(\mathrm{m} \mathrm{s}^{-1}\right)\right]$ value of -7.0 is sufficient to achieve forward rate conditions at $90^{\circ} \mathrm{C}$ which is expected to be the most aggressive condition studied here. Forward rates $\left(R_{\mathrm{B}}, R_{\mathrm{Si}}\right.$ and $\left.R_{\mathrm{Na}}\right)$
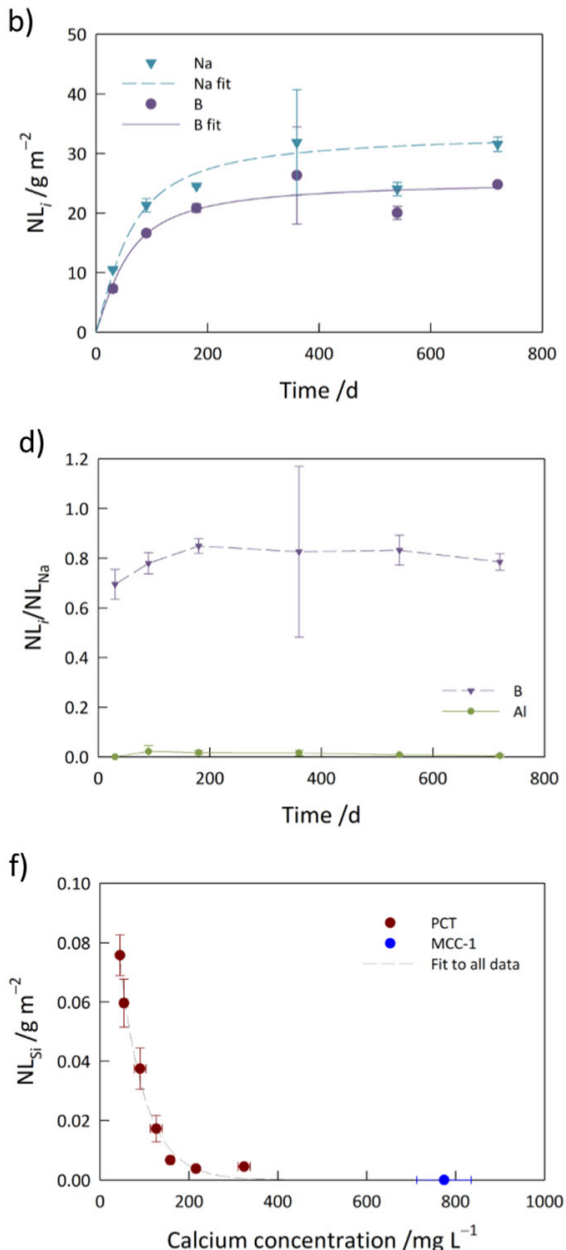

Fig. 2 Leaching data for ISG in saturated $\mathrm{Ca}(\mathrm{OH})_{2}$ solutions: a PCT and $\mathbf{b}$ MCC-1 normalised mass loss of Na and B; $\mathbf{c}$ PCT normalised mass loss of $\mathrm{B}, \mathrm{Al}$ and $\mathrm{Si}$ divided by normalised mass loss of $\mathrm{Na}$ and $\mathbf{d} \mathrm{MCC}-1$ normalised mass loss of $\mathrm{B}$ and $\mathrm{Al}$ divided by normalised mass loss of Na; $\mathbf{e}$ PCT and MCC-1 calcium concentration in solution as a function of time; $\mathbf{f}$ normalised mass loss of Si as a function of Ca concentration in solution. Points are means of two samples and error bars the associated standard deviations. Lines drawn as a guide to the eye except in (a, $\mathbf{b})$ where $\mathrm{NL}_{i}=A \tan ^{-1}\left(\frac{t}{B}\right)$ has been used and (f) where a decaying exponential fit $\left(\mathrm{NL}_{\mathrm{Si}}=0.1616 \exp \left(-0.0175\left[\mathrm{Ca} /\left(\mathrm{mgL}^{-1}\right)\right]\right)\right)$ has been used 
from all experiments are provided in Supplementary Table S2, which also details the experimental conditions and average steady-state concentrations of $\mathrm{B}, \mathrm{Si}$ and $\mathrm{Na}$ in $\mathrm{ppm}$.

The forward dissolution rates of $\mathrm{B}\left(R_{\mathrm{B}}\right)$, as a function of $\mathrm{pH}$ and temperature are shown in Fig. $1 \mathrm{~b}$ together with data from Neeway et al. $^{16}$ demonstrating a good correlation between the two datasets. All of the forward dissolution rate $\left(R_{i}\right)$ data from the basic $\mathrm{pH}$ regime $(\mathrm{pH} 8-12)$ for $\mathrm{B}, \mathrm{Na}$ or $\mathrm{Si}$ were used as input to perform a linear multi-variate regression (LMR) on the following Equation:

$\log _{10}\left(R_{i}\right)=\log _{10}\left(k_{0}\right)-\eta \log _{10}\left(a_{\mathrm{H}^{+}}\right)-\frac{E_{a}}{2.303 R T}$

to extract the rate law parameters $\left(k_{0}, \eta\right.$ and $\left.E_{a}\right)$ in Eq. (1). The parameters determined for all three elements are given in Table 1 and the resultant calculated rates at each temperature studied in the basic $\mathrm{pH}$ regime for $\mathrm{B}$ are shown as solid lines in Fig. $1 \mathrm{~b}$.

Dissolution rates for $\mathrm{Si}$ are compared with other data in the literature in Fig. 1c. In some experiments particles were examined by SEM after the test. This revealed features indicative of localised preferential attack (Fig. 1d) and also what appear to be dehydration cracks (Fig. 1e and Supplementary Figure S2).

\section{Hyperalkaline conditions}

The leaching behaviour of ISG in a saturated $\mathrm{Ca}(\mathrm{OH})_{2}$ solution exhibited the conventional reduction in normalised loss rate with increasing time in both PCT and MCC-1 tests (Fig. 2a, b), although the normalised mass losses for $\mathrm{Na}, \mathrm{B}$ and Al obtained from MCC-1 are significantly larger than those obtained from PCT (compare Fig. $2 a$ with $2 b$ ). The glass particle surface area to solution volume ratio in the PCT tests will reduce with time as the particles agglomerate due to the precipitation of presumed calcium silicate hydrate $(\mathrm{C}-\mathrm{S}-\mathrm{H})$ phases; EDS showed that the phase formed on the surface of the alteration layer was rich in $\mathrm{Ca}$, $\mathrm{Si}$ and $\mathrm{O}$ ( $\mathrm{H}$ not being detectable by EDS) and the needle-like morphology is typical of C$\mathrm{S}-\mathrm{H}$ phases. Although $\mathrm{C}-\mathrm{S}-\mathrm{H}$ precipitation occurred in both $\mathrm{PCT}$ and MCC-1 (see Fig. 3), in PCT most of the Ca was removed from solution by 112 days, whereas with MCC-1 the amount of $\mathrm{Ca}$ in solution remained relatively unchanged even after 720 days, despite a small initial drop during the first 3 months of the test (Fig. 2e). Throughout the MCC-1 test no Si was detected in solution indicating that there was always sufficient excess $\mathrm{Ca}$ present to both react with $\mathrm{Si}$ to form $\mathrm{C}-\mathrm{S}-\mathrm{H}$ phases and to maintain the $\mathrm{Ca}$ concentration in solution. In PCT, Si was detected in solution throughout the test with the concentration increasing with time as the concentration of $\mathrm{Ca}$ in solution decreased (Fig. 2f), after an apparent incubation period of $\sim 3$ days. Based on solution analysis, incongruent leaching was seen in all experiments, with the leaching of $\mathrm{B}$ and $\mathrm{Na}$ being closer to congruent in $\mathrm{MCC}-1\left(\mathrm{NL}_{\mathrm{B}} /\right.$ $\left.\mathrm{NL}_{\mathrm{Na}} \sim 0.8\right)$ than in $\mathrm{PCT}\left(\mathrm{NL}_{\mathrm{B}} / \mathrm{NL}_{\mathrm{Na}} \sim 0.6\right)$ (Fig. $2 \mathrm{C}$, d). Initial normalised loss rates (not to be confused with the forward rate measured in SPFT) and final normalised mass loss rates, $r_{i}$ and $r_{f}$, for $\mathrm{B}$ and $\mathrm{Na}$ release are given in Table 2 . The rates at $t=0$ day and 720 days have been calculated by empirically fitting the $\mathrm{NL}_{i}$ curves with $\mathrm{NL}_{i}=A \tan ^{-1}\left(\frac{t}{B}\right)$; the fits are shown in Fig. 2a, b. The initial values were higher for MCC-1 but the final values were higher for PCT.

Cross-sections of MCC-1 monolith samples exposed to the Ca $(\mathrm{OH})_{2}$ environment for periods of $30-720$ days show the development of a banded alteration region (Fig. 3a-f). From 180 days irregular deposits also appeared on the outermost surface. EDS indicates that the deposits have a $\mathrm{Ca} / \mathrm{Si}$ ratio of $\sim 2.2$ at 180 days that declines to $\sim 1.7$ at 720 days; the Ca/Si ratio of the alteration layer was always lower than that of the precipitates (Table 3). The banded appearance of the alteration layer below the actual glass surface is evident in both secondary (not shown) and back-scattered electron (BE) imaging modes (Fig. 3); elemental mapping has shown the layers to be Ca-rich and alternately $\mathrm{Zr}$-rich and $\mathrm{Zr}$-poor as compared to the original glass (Table 3 and Fig. $3 \mathrm{~h}$ ). In addition, the layer closest to the glass (seen at 180, 540 and 720 days) had a higher Ca content and an intermediate $\mathrm{Zr}$ content compared to the original glass (Fig. $3 \mathrm{~h}$ ). In all of the layers the $\mathrm{Si}$ and $\mathrm{Al}$ content was less than that in the original glass.

Micro-focus XRD performed on a thin section of the 720 day sample, sectioned to analyse the alteration layer, indicated that portlandite $\left(\mathrm{Ca}(\mathrm{OH})_{2}\right.$; PDF card[01-076-0571]) was present. Some additional peaks were also observed (Fig. 3i), however, despite an extensive search no satisfactory match has proven possible. The portlandite is thought to be present in the precipitates formed on the outside of the alteration layer; as the solution that the samples were in contained an excess of $\mathrm{Ca}(\mathrm{OH})_{2}$ powder it is possible that portlandite detected by XRD originated from the solution, rather by precipitating out of solution.

\section{DISCUSSION}

As shown in Fig. 1a, good agreement was found between the data collected in this study and that of Neeway et al. ${ }^{16}$ and the combined data sets were used to obtain the rate parameters in Table 1. Figure 1c shows that the silicon foward rates $\left(R_{\mathrm{Si}}\right)$, obtained at different $\mathrm{pH}$ and $T$ are smaller by factors varying between 2 and 7 than those obtained by Inagaki et al. ${ }^{21}$ using the micro-channel-flow through (MCFT) methodology (depending on specific $\mathrm{pH}$ and temperature, Supplementary Table S3); data obtained at $\log \left[(q / S) /\left(\mathrm{m} \mathrm{s}^{-1}\right)\right]=-5.1$. Fournier et al. ${ }^{22}$ also report a forward rate for $\mathrm{Si}$ obtained at $90^{\circ} \mathrm{C}$ and $\mathrm{pH}\left(90^{\circ} \mathrm{C}\right) 10$ in SPFT of $16.7 \mathrm{~g} \mathrm{~m}^{-2} \mathrm{~d}^{-1}$ (Supplementary Table S3). The data of Fournier et al. were obtained at $\log \left[(q / S) /\left(\mathrm{m} \mathrm{s}^{-1}\right)\right]=-4.8$; this represents very dilute conditions which would give results below the detection limit in the work undertaken here. Thus the difference in results may be due to the higher flow rates used by Inagaki et al. and Fournier et al. The solution pH buffer utilised by Inagaki et al. ${ }^{21}$ contained $\mathrm{KCl}$ and $\mathrm{HCl}$ and that utilised by Fournier et al. ${ }^{22}$ contained $\mathrm{KOH}$; it is possible that $\mathrm{K}$ participated in ion-exchange reactions with alkali elements (i.e., $\mathrm{Na}$ ) in the glass, enhancing the dissolution rate. ${ }^{23}$ Alternatively alkali and alkaline earth salts have also been shown to increase the dissolution rate of both amorphous silica ${ }^{24}$ and crystalline quartz. ${ }^{25}$ In contrast, the use of TRIS buffer, to stabilise the solution in the range $\mathrm{pH}(\mathrm{RT}) 7$ to 9 in this investigation, and more widely utilised ${ }^{17,19,20,26-28}$ precludes these effects, although it has been suggested that TRIS can complex with $\mathrm{B}$ and thus accelerate the dissolution of borosilicate glasses. ${ }^{29}$ However, from $\mathrm{pH}(\mathrm{RT}) 9$ to 11 we did use a $\mathrm{LiCl} / \mathrm{LiOH}$ buffer that could be subject to the same issues. The effects of buffer selection for glass durability assessment requires further investigation.

Although the forward rates measured by Fournier et al. $^{22}$ are in clear disagreement with those calculated from the data considered here, using the data in Table 1 gives a predicted forward rate for the $\mathrm{pH}$ and temperature conditions utilised by Fournier et al. of $4.15_{-3.80}^{+44.9} \mathrm{~g} \mathrm{~m}^{-2} \mathrm{~d}^{-1}$. The very large error bands quoted in this predicted forward rate is due to the fact that a normally distributed error band for $\log _{10}\left(R_{i}\right)$ becomes a log normally distributed error band for $R_{i}$ with a significant asymmetry in the positive and negative error bars. Wider investigations (not detailed here) indicate that similarly large errors in the predicted forward rates, $R_{i}$ (as distinct from $\log _{10}\left(R_{i}\right)$ values) arise with all dissolution data sets reported in the literature especially for higher temperatures and $\mathrm{pH}$ values (see, for example, Corkhill et al.) ${ }^{30}$ Thus while the forward rate measured by Fournier et al. is significantly faster than the rates obtained here, the reported rate actually lies within the error band given by the rate parameters obtained in this work. Reduction of the errors in the predicted rates requires significantly larger data sets to enable a reduction in the individual error terms for the rate parameters. 

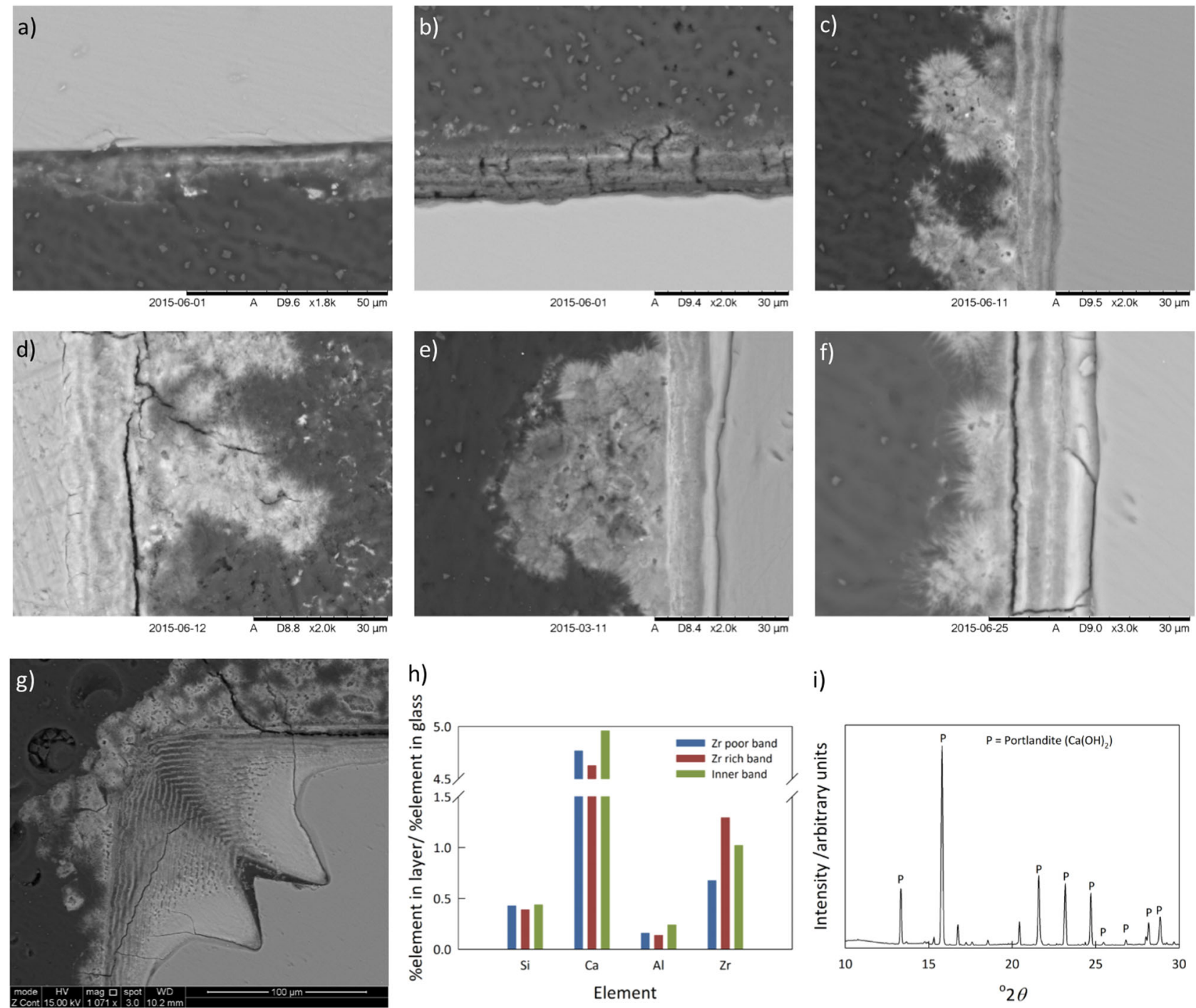

i)

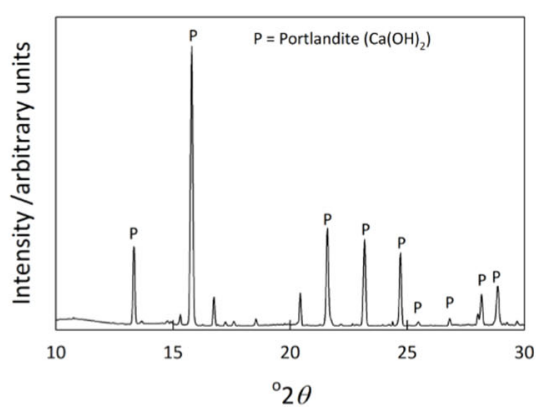

Fig. 3 a-f show back-scattered electron images (BEI) of cross-sections of ISG monoliths after MCC-1 testing in $\mathrm{Ca}(\mathrm{OH})_{2}$ for $30,90,180,360,540$ and 720 days; $\mathbf{g ~ B E I}$ of an ISG monolith cross-section after MCC-1 testing in $\mathrm{Ca}(\mathrm{OH})_{2}$ for 540 days, displaying $>20$ bands in the alteration layer; $\mathbf{h}$ average elemental content of bands in the alteration layer compared to the base glass; i micro-focus XRD pattern of the precipitate region of the 720 day sample

An alternative explanation for the discrepancy in the rates lies in the cracking seen on some particles post-testing (see Fig. 1e). Previously when such features have been observed it has been suggested that they arise from preferential local attack rather than being indicative of dehydration cracking of a hydrated layer under the SEM vacuum. ${ }^{19}$ However, the features marked " $A$ " in Fig. 1d (and Supplementary Figure S2), which clearly do reflect localised chemical attack -in the case of Fig. 1d possibly along pre-existing cracks generated during the powder production process-are quite different from the features marked " $B$ " in Fig. 1e (although we do note that there are some regions of localised attack like features " $A$ " in Fig. 1d apparent in Fig. 1e); the latter are strongly reminiscent of dehydration cracking observed on other SEM samples. The presence of dehydration cracking for these high $\mathrm{pH}$ samples may indicate the formation of a gel layer which would mean that the SPFT was not always yielding true forward rate conditions, presumably due to difficulties in setting suitably high flow rates for the most aggressive solution conditions. In addition, the continued drop in the SPFT dissolution rate with increasing time, as shown in Figure $\mathrm{S} 1 \mathrm{~b}$, indicates that a steady state dissolution rate is not clearly obtained even after 120 days even when a surface area correction is applied. Thus, although the data obtained here are in line with those of Neeway et al., ${ }^{16}$ the possibility that at least some of the data (see, for example, the datapoint for $70^{\circ} \mathrm{C}, \mathrm{pH}(\mathrm{RT}) 11$ in Fig. $1 \mathrm{~b}$ ), and hence the fitted parameters, do not relate to true forward rate conditions cannot be ruled out. However whether we use the current dataset or that of Fournier et al., 22 the question regarding the size of the error bars in any fitted parameters remains.

The rate parameters in Table 1, derived from SPFT, predict the forward rates for $\mathrm{B}$ and $\mathrm{Na}$ at $\mathrm{pH}(\mathrm{RT}) 11.6$ and $50^{\circ} \mathrm{C}$ to be $0.52_{-0.45}^{+3.21} \mathrm{~g} \mathrm{~m}^{-2} \mathrm{~d}^{-1}$ and $0.57_{-0.53}^{+7.95} \mathrm{~g} \mathrm{~m}^{-2} \mathrm{~d}^{-1}$ respectively. The PCT$B$ and MCC-1 experiments involve static solutions so that feedback effects can occur, meaning that the initial rates measured using these protocols are, as expected, lower than the predicted forward rates. For PCT-B the initial rates were lower by a factor of 10 and for MCC-1 they were lower by a factor of 5 . It should also be noted that the PCT-B and MCC-1 data were obtained in a $\mathrm{Ca}(\mathrm{OH})_{2}$ solution, which is not suitable for the SPFT methodology as $\mathrm{Ca}$ $(\mathrm{OH})_{2}$ precipitation on the inlet, and C-S-H precipitation on the outlet, is likely to lead to pipe blockages. However, the ratio of the predicted forward rate for $\mathrm{B}$, to that for $\mathrm{Na}$, is 0.85 , which is similar 
Table 2. Initial $\left(r_{i}\right)$ and final $\left(r_{f}\right)$ normalised mass loss rates for boron and sodium from the $50^{\circ} \mathrm{C} \mathrm{PCT}$ and MCC-1 tests

\begin{tabular}{lllll}
\hline & $r_{\mathrm{i}}(\mathrm{B}) / \mathrm{g} \mathrm{m}^{-2} \mathrm{~d}^{-1}$ & $r_{\mathrm{f}}(\mathrm{B}) / \mathrm{g} \mathrm{m}^{-2} \mathrm{~d}^{-1}$ & $r_{\mathrm{i}}(\mathrm{Na}) / \mathrm{g} \mathrm{m}^{-2} \mathrm{~d}^{-1}$ & $r_{\mathrm{f}}(\mathrm{Na}) / \mathrm{g} \mathrm{m}^{-2} \mathrm{~d}^{-1}$ \\
\hline PCT & $0.051 \pm 0.003$ & $(7.1 \pm 0.1) \times 10^{-4}$ & $0.080 \pm 0.007$ & $(1.11 \pm 0.04) \times 10^{-3}$ \\
MCC- 1 & $0.29 \pm 0.08$ & $(1.12 \pm 0.03) \times 10^{-3}$ & $0.36 \pm 0.06$ & $(2.5 \pm 0.1) \times 10^{-3}$ \\
\hline Rates at $t=0$ day and $t=720$ day calculated by fitting the data with NL$L_{i}=A \tan ^{-1}\left(\frac{t}{B}\right)$, with errors calculated from errors in the fitting parameters
\end{tabular}

to the level of incongruency seen in the MCC-1 data at longer times (see Fig. 2d).

Precipitation of C-S-H phases on the glass surface is in line with previous observations on the behaviour of some ILW glasses in Ca $(\mathrm{OH})_{2}$ solutions, ${ }^{9}$ where the solution can act as the primary source of $\mathrm{Ca}$. Formation of $\mathrm{C}-\mathrm{S}-\mathrm{H}$ phases during the alteration of ISG has also been reported by Gin et al. ${ }^{14}$ and Abdelouas et al., ${ }^{31}$ however these authors observed the precipitation of C-S-H when ISG was altered in a $\mathrm{KOH}$ solution at $\mathrm{pH} 11.5^{14}$ or the formation of tobermorite (a crystalline $\mathrm{C}-\mathrm{S}-\mathrm{H}$ phase) when ISG was altered under different relative humidities. ${ }^{31}$ In both of these cases the $\mathrm{Si}$ and $\mathrm{Ca}$ consumed in forming $\mathrm{C}-\mathrm{S}-\mathrm{H}$ must originate from the glass. Despite this, it is notable that the $\mathrm{Ca} / \mathrm{Si}$ ratios reported by $\mathrm{Gin}$ et al. $(0.60 \pm 0.05$ after 307 days in $\mathrm{KOH})$ and Abdelouas et al. (the $\mathrm{Ca} / \mathrm{Si}$ ratio for tobermorite is 0.83 ) are significantly higher than that of the unaltered glass (0.09). For the $\mathrm{Ca}(\mathrm{OH})_{2}$ solution studied here, due to the external Ca source, the $\mathrm{Ca} / \mathrm{Si}$ ratio of the $\mathrm{C}-\mathrm{S}-\mathrm{H}$ precipitates was significantly higher still at $1.81 \pm 0.18$ after 360 days. Also in the current work the concentration of $\mathrm{Ca}$ in solution dropped significantly, albeit not to zero, during the PCT experiments (Fig. 2e), further indicating that the solution acts as a Ca source for the formation of alteration products, although the presence of some $\mathrm{Ca}$ in the $\mathrm{C}-\mathrm{S}-\mathrm{H}$ products originating from the glass cannot be ruled out by the current experiments. In the MCC1 tests the concentration of $\mathrm{Ca}$ in solution changed only by a limited extent throughout the test (Fig. 2e), while the concentration of $\mathrm{Si}$ in solution remained below detection limits. The much lower glass surface area in the MCC- 1 test, as compared to PCT, means that $\mathrm{C}-\mathrm{S}-\mathrm{H}$ formation, which occurs on the glass surface not elsewhere in the vessel, is able to consume all the available $\mathrm{Si}$ while having only a relatively small effect on the concentration of $\mathrm{Ca}$ in solution. This suggests that there is a reduced level of $\mathrm{Ca}$ in solution that must be achieved before $\mathrm{Si}$ is observed in solution, in agreement with previous observations on a model ILW glass ${ }^{8}$ and a sample of MW-25\% simulant waste glass altered in $\mathrm{Ca}(\mathrm{OH})_{2}{ }^{10}$

The $\mathrm{Ca} / \mathrm{Si}$ values (Table 3 ) measured on the MCC-1 samples suggest that tobermorite-type $(\mathrm{Ca} / \mathrm{Si}=0.83)$ alteration products might form at earlier times, with other phases, such as afwillite $(\mathrm{Ca} / \mathrm{Si}=1.5)$ possibly becoming prevalent later on. However, PHREEQC geochemical modelling suggests that afwillite is in equilibrium (saturation indices of $0.36,0.57,1.00,0.49$ and 0.70 for $90,180,360,540$ and 720 days respectively) and that tobermorite should be supersaturated (saturation indices of 11.61, 12.18, 13.44, 11.97 and 12.63 for tobermorite- $11 \AA$ for $90,180,360,540$ and 720 days respectively) with respect to the leachate solution from 90 days onwards. The $\mathrm{C}-\mathrm{S}-\mathrm{H}$ precipitates have higher $\mathrm{Ca} / \mathrm{Si}$ ratios than the alteration layers for each of the 180, 360, 540 and 720day monoliths, with the ratio decreasing with time. As C-S-H phases with high $\mathrm{Ca} / \mathrm{Si}$ ratios $(\sim 2)$ have not previously been reported for glass dissolution in Ca-rich solutions, this suggests that other, possibly amorphous, Ca-rich, phases may also be present in addition to afwillite and tobermorite. The identification of portlandite rather than calcite by micro-focus XRD results indicates that the $\mathrm{N}_{2}$ atmosphere glovebox successfully prevented carbonation of the samples during the experiments.
The C-S-H precipitates were formed in radiating, acicular clusters on the surface of the alteration layer, but did not form a consistent layer on the surface of the whole sample. The cluster sizes ranged from 4 to $13 \mu \mathrm{m}$ and always appeared on the outside of the sample, rather than within the alteration layer, or between the alteration layer and the glass surface, indicating that they form by precipitation from solution, rather than a re-ordering of the alteration layer. Geochemical modelling with PHREEQC indicates that the formation of crystalline $\mathrm{C}-\mathrm{S}-\mathrm{H}$ precipitates, particularly tobermorite- $9 \AA$, tobermorite- $11 \AA$ and tobermorite- $14 \AA$, is thermodynamically favourable in Ca-rich systems with only a relatively small concentration of $\mathrm{Si}(<10 \mathrm{ppm})$ in solution (see also Jennings ${ }^{32}$ and Corkhill et al. ${ }^{10}$ ); for example the calculations give saturation indices of $2.98,3.92$ and 0.14 for $9 \AA, 11 \AA$ and $14 \AA$ tobermorite respectively after 30 days with a Si concentration of 1 ppm. The PHREEQC calculations also suggest that zeolitic phases might not be expected to be saturated during the dissolution of ISG in $\mathrm{Ca}(\mathrm{OH})_{2}$ (negative saturation index values for all zeolites at all timepoints), although this could be due to insufficient thermodynamic data. No evidence of zeolite formation was seen in this work, which is in contrast to the work of Gin et al. ${ }^{14}$ who observed the formation of zeolites on monolithic samples of ISG in a $\mathrm{KOH}$ leachant, and a consequent resumption of alteration. As the formation of zeolites has been postulated to be responsible for an increased rate of dissolution over longer timescales by Gin and Mestre, ${ }^{33}$ the absence of zeolite phases in this investigation could explain the very significantly lower final normalised mass loss rates reported here compared to those reported by Gin et al., although it should be noted that their experiments were conducted at $90^{\circ} \mathrm{C}$ rather than the $50^{\circ} \mathrm{C}$ used for the MCC- 1 experiments here. In this study, the final normalised mass loss rates calculated for the MCC- 1 experiment were $(1.75 \pm 0.01) \times 10^{-}$ ${ }^{3} \mathrm{~g} \mathrm{~m}^{-2} \mathrm{~d}^{-1}$ for $\mathrm{B}$ and $(2.5 \pm 0.1) \times 10^{-3} \mathrm{~g} \mathrm{~m}^{-2} \mathrm{~d}^{-1}$ for $\mathrm{Na}$, whereas the value for $B$ mass loss rate calculated by Gin et al. for ISG in an equivalent experiment with $\mathrm{KOH}$ as the leachant was $\sim 1.5 \mathrm{~g} \mathrm{~m}^{-2}$ $\mathrm{d}^{-1}$.

A significant feature of the alteration layers seen in the MCC-1 experiments was the presence of Zr-rich and Zr-poor bands; in general the $Z r$-poor bands had a $Z r$ concentration less than that of the original glass whilst the Zr-rich bands had a Zr concentration greater than that of the original glass (see Table 3 and Fig. $3 h$ ). For the 90 day data both the Zr-rich and Zr-poor bands had Zr concentrations in excess of that of the original glass; it is not clear why the 90 day data is different and thus this data is not considered further in the following. Gin et al. have observed the presence of a Zr-rich film on the outer surface of ISG altered at $\mathrm{pH}$ 11.5 in $\mathrm{KOH}$ solution; they suggested that this is due to the reprecipitation of less soluble components following complete glass dissolution, however they did not report the banding seen here. ${ }^{14}$ The formation of a $\mathrm{ZrO}_{2}$ rich layer on the surface of the zirconia containing glasses developed for the reinforcement of cements is believed to be a critical in ensuring the improved durability of these glasses in cementitious environments ${ }^{34,35}$ although again, banding has not been reported. While $\mathrm{ZrO}_{2}$ is generally thought to improve the durability of glasses, especially in alkaline environments, in work on nuclear waste glasses it has been concluded 


\begin{tabular}{|c|c|c|c|c|c|c|}
\hline Time & 30 days & 90 days & 180 days & 360 days & 540 days & 720 days \\
\hline Zr-rich phase & $1.5 \pm 0.2$ & $3.8 \pm 0.5$ & $2.0 \pm 0.2$ & $2.4 \pm 0.2$ & $1.4 \pm 0.3$ & $1.3 \pm 0.2$ \\
\hline Zr-poor phase & $0.8 \pm 0.2$ & $1.7 \pm 0.4$ & $0.6 \pm 0.1$ & $0.8 \pm 0.2$ & $0.8 \pm 0.3$ & $1.0 \pm 0.1$ \\
\hline Zr-poor phase & $0.60 \pm 0.08$ & $1.04 \pm 0.07$ & $1.42 \pm 0.20$ & $1.46 \pm 0.14$ & $1.55 \pm 0.14$ & $1.39 \pm 0.16$ \\
\hline C-S-H precipitates & ND & ND & $2.19 \pm 0.11$ & $1.81 \pm 0.18$ & $1.89 \pm 0.21$ & $1.73 \pm 0.21$ \\
\hline
\end{tabular}

that the presence of zirconia in an alteration layer impedes reorganisation of that layer ${ }^{36,37}$ and thus can impact negatively on the longer term durability of the glass. It seems likely that the glass has to contain a certain minimum concentration of $\mathrm{ZrO}_{2}$ for any $\mathrm{Zr}$ enriched layer to form; in some associated work on a Magnox waste glass, that contains approximately $50 \%$ of the $\mathrm{ZrO}_{2}$ in ISG, no $\mathrm{Zr}$-rich regions were identified on the surface of the samples. ${ }^{38}$

Banded alteration layers have been reported on glass surfaces in a number of cases including many archaeological glasses. Although climatic variations have been suggested as an explanation of banding in archaeological samples, in laboratory experiments such as those considered here constant external conditions are imposed and thus some type of self-organisation phenomenon is required to explain the formation of the layers. Geisler and co-workers have suggested that banding in the alteration layers on the surface of glass can be explained by a self-organisation process involving coupled dissolution-reprecipitation on the surface of glass. ${ }^{39,40}$ They argue that the underlying glass dissolution is congruent throughout, but that after the initial stage of dissolution, a silica gel layer develops and as this ripens, glass dissolution continues at the interface behind a silica gel layer. This model suggests that local compositional and $\mathrm{pH}$ changes occur in the pore solution that is present between the silica gel layer and the glass surface, and that diffusion of the species from the pore solution to the bulk solution is limited by the silica gel layer. These local compositional variations and $\mathrm{pH}$ changes can then lead to the development of layered structures such as those observed here. As noted above the solution can act as the Ca source and hence Ca content of the alteration layer is $\sim 5$ times higher than the original glass (Fig. $3 \mathrm{~h}$ ). Figure $3 \mathrm{~g}$ also shows that the $\mathrm{Si}$ and $\mathrm{Al}$ contents of all of the bands in the alteration layer are less than that of the original glass, and that the $\mathrm{Al} / \mathrm{Si}$ ratios are decreased compared to the original glass. Congruent dissolution of the glass would result in $\mathrm{Si}$ enrichment of the $\mathrm{Ca}$ $(\mathrm{OH})_{2}$ solution leading to the precipitation of $\mathrm{C}-\mathrm{S}-\mathrm{H}$ or, based on the Al content, C-A-S-H phases (Fig. 3h). Apart from the $\mathrm{Zr}$ content the $\mathrm{Zr}$-rich and $\mathrm{Zr}$-poor bands had similar compositions (Ca:Al:Si ratios of 1.53:0.05:1 and 1.44:0.06:1 respectively, averaged over the samples from the latter 4 time points); the inner layer differed slightly with a Ca:Al:Si ratio of 0.95:0.06:1. Solubility of $\mathrm{Zr}$ varies with $\mathrm{pH}$ and thus local variations of $\mathrm{pH}$ such as those proposed by Geisler and co-workers could explain the observed banding, although some variation in the other gel components might also have been expected.

Recently Wang et al. ${ }^{41}$ have proposed a mathematical model for a self-organising system that leads to the development of bands with time. In the current work however, there is no clear evolution in either the number or the thickness of the bands with time, although there is some compositional evolution at early times (see Table 3). In addition localised areas with large numbers of bands have been observed (Fig. 3g); it is notable that the feature in Fig. $3 \mathrm{~g}$ has a more complex surface profile than the areas shown in Fig. 3a-f, which might have led to more rapid local variations in solution concentration and thus an increased number of bands. However the lack of a clear time dependence for layer formation means that the model of Wang et al. cannot be readily applied to the current data.

Overall in this paper

1. Rate parameters for ISG have been derived from SPFT data. The ISG forward rate data reported here for the $\mathrm{pH}$ range 8-12 and temperatures of $40-70{ }^{\circ} \mathrm{C}$ are consistent with those of Neeway et al. ${ }^{16}$ While the discrepancies between the rate data reported here and by others may be due to differences in flow rates and buffer solutions it is notable that they are within the error bands of the rates predicted from the rate parameters, due to the large asymmetric rate parameter error bands that arise from using data fitted on a logarithmic function.

2. There is evidence of localized preferential attack and dehydration cracking on the surface of some particles from the SPFT conducted under the most aggressive (highly $\mathrm{pH}$ ) conditions. In addition, longer duration SPFT experiments indicate that true steady state was not always achieved. Hence aspects of the SPFT protocol may need revisiting.

3. MCC -1 tests showed that Ca rich (compared to the base glass) alteration layers and $\mathrm{C}-\mathrm{S}-\mathrm{H}$ alteration products form after 30 days and 180 days, respectively, on the surface of ISG altered in a $\mathrm{Ca}(\mathrm{OH})_{2}$, solution at $50^{\circ} \mathrm{C}(\mathrm{pH}=11.6, \mathrm{SA} / \mathrm{V}=$ $\left.10 \mathrm{~m}^{-1}\right)$. The $\mathrm{Ca} / \mathrm{Si}$ ratio of the alteration products is initially high and decreases with further increases in immersion time, whereas the $\mathrm{Ca} / \mathrm{Si}$ ratio of the alteration layer starts low and increases when the $\mathrm{C}-\mathrm{S}-\mathrm{H}$ alteration products form.

4. $\mathrm{Zr}$ banding is seen within the alteration layer at all immersion times tested in the high $\mathrm{pH}$ MCC- 1 experiments. The formation of bands indicates that some form of selforganisation process must occur during the dissolution of ISG, although no clear time dependence is observed.

\section{METHODS}

Glass fabrication and preparation

The ISG was fabricated in 2012 by the MoSci Corporation (Rolla, MO, USA), as described by Gin et al. ${ }^{14}$ The lot number of the batch used in all experiments was L1201 2601-M1205 0803. The ISG was crushed and sieved to a size fraction of $75-150 \mu \mathrm{m}$ diameter (used in SPFT and PCT-B investigations) and the intial surface area, $S_{0}$, of the crushed glass was calculated using the geometric formula, assuming spherical particles ${ }^{17}$

$S_{0}=\frac{3 m}{\rho r_{0}}$ 
where $m$ is the mass of the glass sample in $g, \rho$ is the glass density $\left(2.50 \mathrm{Mg} \mathrm{m}^{-3}\right.$ for the ISG, measured in this investigation by helium pycnometry and also by Gin et al. $)^{42}$ and $r_{0}$ is the the average initial particle radius in $\mathrm{m}$.

$10 \times 10 \times 5 \mathrm{~mm}$ coupons were cut from a section of glass using a Buehler IsoMet ${ }^{\circledR}$ Low-speed Saw with a Buehler Series 15 LC wafering blade, lubricated with Buehler IsoCut ${ }^{\circledR}$ fluid. The coupons were ground to a P800 finish using a Buehler EcoMet 250 Pro, with Buehler SiC abrasive paper. The ground coupons were cleaned ultrasonically for $5 \mathrm{~min}$ in ultra-high quality (UHQ) water and then in isopropanol for $3 \times 5 \mathrm{~min}$, with fresh isopropanol used for each period. After cleaning, the coupons were stored in a desiccator until required.

\section{Solution preparation}

Acidic and alkaline experiments (SPFT). Buffer solutions with $\mathrm{pH}$ (measured at room temperature - RT) 7, 9 and 11 were prepared from measured amounts of organic tris hydroxymethyl aminomethane buffer (TRIS) (0.01, 0.05 and $0.05 \mathrm{M}$, respectively) added to $\mathrm{UHQ}\left(18.2 \mathrm{M} \Omega \mathrm{cm}^{-1}\right)$ water, adjusted to the desired $\mathrm{pH}$ values with $15 \mathrm{M} \mathrm{HNO}_{3}$. The $\mathrm{UHQ}$ water was produced by a Millipore Direct-Q (UV) 3 water purification system. Buffer solutions for $\mathrm{pH} 11$ and 12 were prepared from $0.01 \mathrm{M} \mathrm{LiCl}$ and ultra-high quality $(18.2 \mathrm{M} \Omega \mathrm{cm})$ water and were adjusted to the desired $\mathrm{pH}$ values with $1 \mathrm{M} \mathrm{LiOH}$. In the acidic range, buffer solutions for $\mathrm{pH}(\mathrm{RT}) 4.5$ and 5.5 were prepared from $0.01 \mathrm{M} \mathrm{HNO}_{3}$ added to UHQ water, adjusted to the desired $\mathrm{pH}$ with $9.9 \times 10^{-3} \mathrm{M} \& 1 \times 10^{-2}$ ammonium hydroxide $\left(\mathrm{NH}_{4} \mathrm{OH}\right)$ respectively. ${ }^{43}$ Supplementary Table 3 shows the $\mathrm{pH}$ (RT) and the modelled $\mathrm{pH}$ at the experimental temperatures. These modelled values were computed using PHREEQC geochemical modelling and EQ3NR thermodynamic software packages. ${ }^{19,44}$

Hyperalkaline experiments (PCT-B and MCC-1). All leach tests and solution preparations were carried out in a flowing nitrogen atmosphere, in a glovebox, to prevent carbonation; leach tests were conducted at $50^{\circ} \mathrm{C}$ using a LT Scientific OP39-UF oven. $\mathrm{Ca}(\mathrm{OH})_{2}$ solutions: nitrogen was first bubbled through UHQ water, for $>24 \mathrm{~h}$ to remove $\mathrm{CO}_{2}$. The $\mathrm{Ca}(\mathrm{OH})_{2}$ leachant was produced by adding an excess of $\mathrm{Ca}(\mathrm{OH})_{2}$ powder $(>0.92 \mathrm{~g}$ $\mathrm{L}^{-1}$ ) to UHQ water in a HDPE vessel. It was then shaken vigorously in order to achieve full dissolution of the $\mathrm{Ca}(\mathrm{OH})_{2}$, and allowed to sit for several hours in order for the excess $\mathrm{Ca}(\mathrm{OH})_{2}$ to settle to the bottom of the vessel. The solution was filtered prior to the PCT-B experiments.

\section{Leaching experiments}

SPFT methodology. The SPFT method is a standard dynamic dissolution test in which fresh solution constantly flows over a sample. ${ }^{17,20,27,45-48}$ In this investigation, pump flow-rates varied from $10-80 \mathrm{~mL} \mathrm{~d}^{-1}$ for the initial $q / S$ sweep (Supplementary Table S1) and the mass of the ISG sample varied between $0.29-1 \mathrm{~g}$. The experimental parameters used for determining dissolution rates and the range of temperature $\left(40,50\right.$ and $\left.70^{\circ} \mathrm{C}\right)$ and $\mathrm{pH}$ (RT) (4.5-11) values chosen to ascertain the rate law parameters described in Eq. (1) are provided in Supplementary Table S2.

Effluent samples were collected at regular intervals and flow-rates determined gravimetrically. The elemental release was measured by analysing effluent solution for $\mathrm{Si}, \mathrm{B}, \mathrm{Na}$ and $\mathrm{Al}$ concentrations using inductively coupled plasma optical emission spectroscopy (ICP-OES, ThermoScientific iCAPDuo6300). All tests were performed until the elemental releases and thus normalised $\mathrm{B}, \mathrm{Si}$ and $\mathrm{Na}$ dissolution rates attained steady-state conditions. Steady-state conditions were defined by having at least three dissolution rate measurements near the end of the test (to eliminate the influence of dissolving fine fragments attached to the glass particles) that did not deviate by more than $15 \%$ from their mean value and where the sample had lost no more than $30 \%$ of its original surface area. The mean dissolution rate from $\geq 3$ measurements at steadystate for each test was then recorded.

Dissolution rates were calculated using:

$r_{i}=\frac{\left(C_{i}-C_{i, 0}\right) q}{f_{i} S}$

where $r_{i}$ represents the normalised dissolution rate of element $i=\mathrm{Si}, \mathrm{B}, \mathrm{Na}$ or Al) in $\mathrm{g} \mathrm{m}^{-2} \mathrm{~d}^{-1}, C_{i}$ the concentration of element $i$ in the effluent solution $\left(\mathrm{mg} \mathrm{L}^{-1}\right), C_{i, 0}$ is the background concentration of element $i$ in the input buffer solution (both in $\mathrm{mg} \mathrm{L}^{-1}$ ), and $f_{i}$ the mass fraction of element $i$ in the glass (unitless). Note that the surface area, $S$, changes throughout the duration of the experiment as the glass dissolves.
A surface area correction model developed by McGrail et al. ${ }^{17}$ was applied to calculate the change in $S$. This correction determined the mass of glass $m_{j}(\mathrm{~g})$ that remained at each time interval $(j)$ :

$m_{j}=m_{0}-\frac{1}{f_{i}}\left[\sum_{k=1}^{j-1} q_{k} C_{k, i} \Delta t_{k}+q_{j} C_{j, i} \frac{\Delta t_{j}}{2}\right] \quad j \geq 1$

where $m_{0}$ is the initial mass of the glass (g) (Supplementary Tables S1 and S2) and the summation term represents the accumulated mass loss from time step $k=1$ to time step $j-1$, calculated based on B loss $\left(C_{B}\right)$. The second term (in the brackets) represents the average total mass loss from time step $j-1$ to $j$. Hence, the surface area at time point $j, S_{j}\left(\mathrm{~m}^{2}\right)$, can be using:

$S_{j}=\frac{3}{\rho r_{0}} m_{0}^{1 / 3} m_{j}^{2 / 3}$

Modifications to the rate data due to the application of the shrinking core model are demonstrated in Supplementary Figure S1b. Determination of the experimental uncertainty of the dissolution rates accounted for the uncertainty associated with each parameter described in Eq. (4). For these uncorrelated random errors, the standard deviation of a function $f\left(x_{i}\right)$ is given by:

$\sigma_{f}=\sqrt{\sum_{i=1}^{n}\left(\frac{\partial f}{\partial x_{i}}\right)^{2} \sigma_{i}^{2}}$

where $\sigma_{f}$ is the standard deviation of $f\left(x_{i}\right), x_{i}$ is the parameter pertaining to element $i$ and $\sigma_{i}$ is is the standard deviation of parameter $\sigma_{i}$. Substituting Eq. (4) into Eq. (7), and using a relative error, $\hat{\sigma}_{r_{i}}=\frac{\sigma_{r_{i}}}{r_{i}}$ gives

$\hat{\sigma}_{r_{i}}=\sqrt{\frac{\left(\hat{\sigma}_{C_{i, s}} C_{i, s}\right)^{2}+\left(\hat{\sigma}_{C_{i, b}} C_{i, 0}\right)^{2}}{\left(C_{i, s}-C_{i, 0}\right)^{2}}+\hat{\sigma}_{q}^{2}+\hat{\sigma}_{f, i}^{2}+\hat{\sigma}_{S}^{2}}$

from which the experimental uncertainty on $r_{i}$ can be derived. Relative errors of $10 \%, 10 \%, 3$ and $15 \%$ were ascribed to $C_{i}, C_{i, o}, f_{i}$ and $S$ respectively and errors between 5 and $15 \%$ were ascribed to $q$ values based on gravimetric measurements.

PCT-B methodology. Powdered samples (75-149 $\mu \mathrm{m}$ particle size fraction) were washed and prepared in accordance to the ASTM standard. ${ }^{49}$ Tests were carried out at $50^{\circ} \mathrm{C}$ in a $500 \mathrm{~mL}$ HDPE vessel, with $400 \mathrm{~mL}$ of leachant and $\sim 22.8 \mathrm{~g}$ of glass to give a glass-surface area-to-leachant-volume (SA/V) of $1200 \pm 60 \mathrm{~m}^{-1}$; in line with our previous work on the effects of $\mathrm{Ca}(\mathrm{OH})_{2}$ solutions. ${ }^{8,9}$ An Advantec USY-1 ultrafilter unit filled with a slurry of $\mathrm{Ca}$ $(\mathrm{OH})_{2}$ powder and UHQ water, was added to the test vessel in order to maintain the $\mathrm{pH}$ of the leachant. Duplicate tests and two blanks were run for $1,3,7,14,28,56$ and 112 days.

MCC-1 methodology. Following the ASTM standard ${ }^{50}$ monoliths were placed onto perfluoralkoxy (PFA) teflon baskets, to prevent direct contact with the excess $\mathrm{Ca}(\mathrm{OH})_{2}$, in a Savillex $60 \mathrm{ml}$ PFA teflon standard jars, with $40 \mathrm{ml}$ of the $\mathrm{Ca}(\mathrm{OH})_{2}$ solution giving an SA/ $\mathrm{N}$ of $10 \mathrm{~m}^{-1}$. Tests were conducted in duplicate with two blanks at $50^{\circ} \mathrm{C}$ for $30,90,180,360,540$ or 720 days. After testing altered coupons were gently rinsed with $\sim 2 \mathrm{~mL}$ $\mathrm{UHQ}$ water, in order remove any remaining $\mathrm{Ca}(\mathrm{OH})_{2}$ without washing off precipitates. The altered coupons were not sectioned after removal from solution, but each intact coupon was mounted in epoxy resin, ground to a P1200 grit finish on a Buehler EcoMet 250 Pro, then polished using 6, 3 and $1 \mu \mathrm{m}$ diamond paste, and analysed using scanning electron microscopy (SEM; either on a Hitachi TM3030 desktop microscope or an FEl Inspect F) and energy dispersive $\mathrm{x}$-ray spectroscopy (EDX). Triplicate EDX measurements were taken for each phase at each time point.

Micro-focus $X$-ray diffraction $(\mu-X R D)$. Data were collected on a thinsection of the 720-day MCC-1 monolith on the microXAS (X05LA) beamline at the Swiss Light Source, Paul Scherrer Institute, Switzerland. The section was mounted onto a glass slide placed on a motorised stage positioned at an angle of $25^{\circ}$ to the monochromatic incident $17.2 \mathrm{keV}$ beam, which had a spot size of $7 \mu \mathrm{m}$ by $2 \mu \mathrm{m}$. The diffraction patterns were measured with a PILATUS $100 \mathrm{~K}$ hybrid pixel array detector mounted $46 \mathrm{~mm}$ behind the sample with a W beamstop in place. A Si standard was used for calibration.

Solution analysis. On completion of SPFT, PCT-B and MCC-1 tests, $5 \mathrm{~mL}$ aliquots of leachate were taken, of which $4 \mathrm{~mL}$ were acidified with 1 vol. \% 
$69 \% \mathrm{HNO}_{3}$ and analysed by ICP-OES (ThermoFisher iCAPDuo 6300) and $1 \mathrm{~mL}$ used for $\mathrm{pH}$ measurement.

\section{DATA AVAILABILITY}

The data that support the findings of this study are available from the corresponding author upon reasonable request.

\section{ACKNOWLEDGEMENTS}

The authors wish to thank ISL members (TUoS) assisting data collection and Eunja Kim (AWE) for the loan of additional SPFT equipment. Funding for D.J.B. came from the EPSRC Nuclear FiRST Centre for Doctoral Training by provision of a studentship under grant EP/G037140/1 and for A.J.F. from the Next Generation Nuclear Centre for Doctoral Training by provision of a studentship under grant EP/L015390/1. Financial support for C.L.C. from the EPSRC (ECR Fellowship; EP/N017374/1) and for N.C.H. the Royal Academy of Engineering, UK and the Nuclear Decommissioning Authority, UK is also acknowledged. Funding for J.J.N. came from the U.S. Department of Energy (DOE) through the Office of Nuclear Energy's Nuclear Technology Research and Development Program. This research was performed in part at the MIDAS Facility, at the University of Sheffield, which was established with support from the UK Department of Energy and Climate Change. Access to the Swiss Light Source, Paul Scherrer Institute, Villigen, Switzerland, was supported by the TALISMAN collaborative project, with co-funding from the European Commission under the Euratom Research and Training Programme on Nuclear Energy, within the 7th Framework programme (grant agreement 323300).

\section{AUTHOR CONTRIBUTIONS}

All authors provided substantial contributions to conception of the research performed, or the acquisition, analysis or interpretation of the data; they drafted or revised the manuscript; approved the final version and are accountable for the accuracy and integrity of the data and its interpretation.

\section{ADDITIONAL INFORMATION}

Supplementary information accompanies the paper on the npj Materials Degradation website (https://doi.org/10.1038/s41529-018-0050-5).

Competing interests: The authors declare no competing interests.

Publisher's note: Springer Nature remains neutral with regard to jurisdictional claims in published maps and institutional affiliations.

\section{REFERENCES}

1. Vasconcelos, R. G. W. et al. Characterisation of a high pH cement backfill for the geological disposal of nuclear waste: The Nirex Reference Vault Backfill. Appl. Geochem. 89, 180-189 (2018).

2. Boksay, Z., Bouquet, G. \& Dobos, S. Diffusion processes in surface layers of glass. Phys. Chem. Glass. 8, 140-144 (1967).

3. Sanders, D. M. \& Hench, L. L. Mechanisms of glass corrosion. J. Am. Ceram. Soc. 56, 373-377 (1973)

4. Eyring, H. The activated complex in chemical reactions. J. Chem. Phys. 3, 107-114 (1935).

5. Aagaard, P. \& Helgeson, H. C. Thermodynamic and kinetic constraints on reaction rates among minerals and aqueous solutions. I. Theoretical considerations. Am. J. Sci. 282, 237-285 (1982).

6. Grambow, B. in Scientific Basis for Nuclear Waste Management VIII, MRS Proceedings, Vol. 44, (eds Jantzen C. M., Stone J. A. \& Ewing R. C.) pp. 15-27, Materials Research Society, Pittsburgh, PA (1985).

7. Lasaga, A. C. Fundamental approaches in describing mineral dissolution and precipitation rates. In Reviews in Mineralogy, Chemical Weathering Rates of Silicate Minerals. Min. Soc. Amer 31, 353-406 (1995).

8. Utton, C. A. et al. Dissolution of vitrified wastes in a high-pH calcium-rich solution. J. Nucl. Mater. 435, 112-122 (2013).

9. Utton, C. A., Hand, R. J., Hyatt, N. C., Swanton, S. W. \& Williams, S. J. Formation of alteration products during dissolution of vitrified ILW in a high-pH calcium-rich solution. J. Nucl. Mater. 442, 33-45 (2013).

10. Corkhill, C. L., Cassingham, N. J., Heath, P. G. \& Hyatt, N. C. Dissolution of UK highlevel waste glass under simulated hyperalkaline conditions of a collocated geological disposal facility. Int. J. Appl. Glass Sci. 4, 341-356 (2013).
11. Mercado-Depierre, S., Angeli, F., Frizon, F. \& Gin, S. Antagonist effects of calcium on borosilicate glass alteration. J. Nucl. Mater. 441, 402-410 (2013).

12. Andriambololona, Z., Godon, N. \& Vernaz, E. in Scientific Basis for Nuclear Waste Management, XV, MRS Proceedings, Vol. 257, (ed C. G. Sombret C. G.) pp. 151-158, Materials Research Society, Pittsburgh, PA (1992).

13. Chave, T., Frugier, P., Gin, S. \& Ayral, A. Glass-water interphase reactivity with calcium rich solutions. Geochim. Cosmochim. Acta 75, 4125-4139 (2011).

14. Gin, S. et al. The fate of silicon during glass corrosion under alkaline conditions: A mechanistic and kinetic study with the International Simple Glass. Geochim. Cosmochim. Acta 151, 68-85 (2015).

15. Gin, S. et al. An international initiative on long-term behaviour of high-level nuclear waste glass. Mater. Today 16, 243-248 (2013).

16. Neeway, J. J., Rieke, P. C., Parruzot, B. P., Ryan, J. V. \& Asmussen, R. M. The dissolution behaviour of borosilicate glasses in far-from equilibrium conditions. Geochim. Cosmochim. Acta 226, 132-148 (2018).

17. McGrail, B. P., Ebert, W. L., Bakel, A. J. \& Peeler, D. K. Measurement of the kinetic rate law parameters on a Na-Ca-Al borosilicate glass for low activity waste. J. Nucl. Mater. 149, 175-189 (1997).

18. McGrail B.P. et al. Low-activity waste glass studies: FY 2000 summary report. PNNL13381 (2000)

19. Pierce, E. M. et al. Experimental determination of the effect of the ratio of $\mathrm{B} / \mathrm{Al}$ on glass dissolution along the nepheline $\left(\mathrm{NaAlSiO}_{4}\right)$-malinkoite $\left(\mathrm{NaBSiO}_{4}\right)$ join. Geochim. Cosmochim. Acta 74, 2634-2654 (2010).

20. Cassingham, N. J. et al. The initial dissolution rates of simulated UK MagnoxThORP blend nuclear waste glass as a function of $\mathrm{pH}$, temperature and waste loading. Miner. Mag. 79, 1529-1542 (2015).

21. Inagaki., Y., Kikunaga, T., Idemitsu, K. \& Arima, T. Initial dissolution rate of the international simple glass as a function of $\mathrm{pH}$ and temperature measured using microchannel flow-through test method. Int. J. Appl. Glass Sci. 4, 317-327 (2013).

22. Fournier, M. et al. Glass dissolution rate measurement and calculation revisited. J. Nucl. Mater. 476, 140-154 (2016).

23. Neeway, J. J. et al. lon-exchange interdiffusion model with potential application to long-term nuclear waste glass performance. J. Phys. Chem. C 120, 9374-9384 (2016).

24. Icenhower, J. P. \& Dove, P. M. The dissolution kinetics of amorphous silica into sodium chloride solutions: effects of temperature and ionic strength. Geochim. Cosmochim. Acta 64, 4193-4203 (2000).

25. Dove, P. M. \& Nix, C. J. The influence of the alkaline earth cations, magnesium, calcium, and barium on the dissolution kinetics of quartz. Geochim. Cosmochim Acta 61, 2229-3340 (1997).

26. Icenhower, J. P. et al. Experimentally determined dissolution kinetics of Na-rich borosilicate glass at far from equilibrium conditions: implications for Transition State Theory. Geochim. Cosmochim. Acta 72, 2767-2788 (2008).

27. Icenhower, J. P. \& Steefel, C. I. Experimentally determined dissolution kinetics of SON68 glass at $90{ }^{\circ} \mathrm{C}$ over a silica saturation interval: evidence against a linear rate law. J. Nucl. Mater. 439, 137-147 (2013).

28. Hopf et al. Glass-water interaction: effect of high-valence cations on glass structure and chemical durability. Geochim. Cosmochim. Acta 181, 54-71 (2016).

29. Tournié, A. et al. Impact of boron complexation by Tris buffer on the initial dissolution rate of borosilicate glasses. J. Colloid Interface Sci. 400, 161-167 (2013).

30. Corkhill, C. L., Fisher, A. J., Strachan, D. M., Hand, R. J. \& Hyatt, N. C. Corrigendum to "The dissolution rates of simulated Magnox-ThORP blend nuclear waste glass as a function of $\mathrm{pH}$, temperature and waste loading" [Miner. Mag. 79 (2015) 1529-1542]. Min. Mag., In Press, https://doi.org/10.1180/minmag.2017.081.077.

31. Abdelouas, A. et al. A preliminary investigation of the ISG glass vapor hydration. Int. J. Appl. Glass Sci. 4, 307-316 (2013).

32. Jennings, H. M. Aqueous solubility relationships for two types of calcium silicate hydrate. J. Am. Ceram. Soc. 69, 614-618 (1986).

33. Gin, S. \& Mestre, J. P. SON 68 nuclear glass alteration kinetics between $\mathrm{pH} 7$ and pH 11. J. Nucl. Mater. 295, 83-96 (2001).

34. Larman, L. J., Speakman, K. \& Majumdar, A. J. Chemical interactions between glass fibres and cement. J. Non-Cryst. Solids 20, 43-74 (1976).

35. Purnell, P. \& Beddows, J. Durability and simulated ageing of new matrix glass fibre reinforced concrete. Cem. Concr. Compos. 27, 875-884 (2005).

36. Cailleteau, C. et al. Insight into silicate-glass corrosion mechanisms. Nat. Mater. 7 978-983 (2008)

37. Arab, M. et al. Aqueous alteration of five-oxide silicate glasses: experimental approach and Monte Carlo modelling. J. Non-Cryst. Solids 354, 155-161 (2008).

38. Backhouse D. J. A study of the dissolution of nuclear waste glasses in highly-alkaline conditions PhD thesis, http://etheses.whiterose.ac.uk/16760/ (University of Sheffield, 2017).

39. Dohmen, L. et al. Pattern formation in silicate glass corrosion zones. Int. J. Appl. Glass Sci. 4, 357-370 (2013). 
40. Geisler, T. et al. The mechanism of borosilicate glass corrosion revisited. Geochim. Cosmochim. Acta 158, 112-129 (2015).

41. Wang, Y., Jove-Colon, C. F. \& Kuhlman, K. L. Nonlinear dynamics and instability of aqueous dissolution of silicate glasses and minerals. Sci. Rep. 6, 30256 (2016).

42. Gin., S., Beaudoux, X., Angeli, F., Jégou., C. \& Godon, N. Effect of composition on the short-term and long-term dissolution rates of ten borosilicate glasses of increasing complexity from 3 to 30 oxides. J. Non-Cryst. Solids 358, 2559-2570 (2012).

43. Wellman, D. M., Gunderson, K. M., Icenhower, J. P. \& Forrester, S. W. Dissolution kinetics of synthetic and natural meta-autunite minerals, $\mathrm{X}_{(3-n)}{ }^{(n)+}\left[\left(\mathrm{UO}_{2}\right)\right.$ $\left.\left(\mathrm{PO}_{4}\right)\right]_{2} \cdot \mathrm{xH}_{2} \mathrm{O}$, under acidic conditions. Geochem. Geophys. Geosys. 8, 1-16 (2007).

44. Wolery, T. J. EQ3NR, A computer code for geochemical aqueous speciation-solubility calculations: theoretical manual, user's guide and related documentation (Version 7.0). (Lawrence Livermore National Laboratory, Livermore, CA, 1992). UCRL-MA110662 PT 1.

45. Abraitis, P. K., McGrail, B. P., Trivedi, D. P., Livens, F. R. \& Vaughan, D. J. Single-passflow-through experiments on a simulated waste glass in alkaline media at $40^{\circ} \mathrm{C}$. 1. Experiments conducted at variable solution flow rate to glass surface area ratio. J. Nucl. Mater. 280, 196-205 (2000).

46. Standard practice for measurement of the glass dissolution rate using the singlepass flow-through test method ASTM C1662-17 (2017).

47. McGrail, B. P. \& Peeler, D. K. Evaluation of the single-pass flow-through test to support a low-activity waste specification. (Pacific Northwest Laboratory, Richmond, Washington, 1995). PNL-10746.
48. Pierce, E. M., Rodriguez, E. A., Calligan, L. J., Shaw, W. J. \& McGrail, B. P. An experimental study of the dissolution rates of simulated aluminoborosilicate waste glasses as a function of $\mathrm{pH}$ and temperature under dilute conditions. Appl. Geochem. 223, 2559-2573 (2008).

49. Standard test methods for determining chemical durability of nuclear, hazardous, and mixed waste glasses and multiphase glass ceramics: the product consistency test (PCT) ASTM C1285-02 (2008).

50. Standard Test Method for Static Leaching of Monolithic Waste Forms for Disposal of Radioactive Waste ASTM C1220-17 (2017).

Attribution 4.0 International License, which permits use, sharing, adaptation, distribution and reproduction in any medium or format, as long as you give appropriate credit to the original author(s) and the source, provide a link to the Creative Commons license, and indicate if changes were made. The images or other third party material in this article are included in the article's Creative Commons license, unless indicated otherwise in a credit line to the material. If material is not included in the article's Creative Commons license and your intended use is not permitted by statutory regulation or exceeds the permitted use, you will need to obtain permission directly from the copyright holder. To view a copy of this license, visit http://creativecommons. org/licenses/by/4.0/.

(c) The Author(s) 2018 